\title{
“Of Fear and Hope”, A Reflexive Ethnography of Uncertainty Following A Needle Stick Injury
}

\section{Prince Kyei Baffour}

Burns Intensive Care Unit, Directorate of Surgery, Komfo Anokye Teaching Hospital, Kumasi- Ghana

${ }^{\star}$ Corresponding author: Prince Kyei Baffour, Burns Intensive Care Unit, Directorate of Surgery, Komfo Anokye Teaching Hospital, Kumasi- Ghana, C/O Box 1934, Kumasi; Email: princekyeibaffour@yahoo.com

Received Date: August 18, 2019 Accepted Date: September 17, 2019 Published Date: September 19, 2019

Citation: Prince Kyei Baffour (2019) “Of Fear and Hope”, A Reflexive Ethnography of Uncertainty Following A Needle Stick Injury. J HIV AIDS Infect Dis 5: 1-7.

\begin{abstract}
The causes and effects of needle stick injuries have been widely investigated but it remains unclear how individual practitioners navigate through the experience of having this form of injury and the possible outcomes associated with it. To this end, the author takes readers on his journey of the emotional negotiations after experiencing a needle stick injury whilst working with a patient who was later identified to be positive with the Human Immunodeficiency Virus (HIV). A reflexive ethnography approach is used where the self is the focus of the exploration. In the exploration, the author recounts the mixed nuances of emotions and psychological trauma that filled the journey coupled with having to deal with the physical effects of post-exposure prophylaxis. At the end of the journey, the author posits the need for institutional support for needle stick injury victims in the facility which should be structured in a "support team to victim approach".

Keywords: Needlestick injury; Post Exposure Prophylaxis; Reflexive Ethnography; Nurses
\end{abstract}




\section{Introduction}

Needlestick injuries (NSI) usually occur when a healthcare worker experiences a break in the skin resulting from contact with needles or sharp objects that have been in contact with a patient's blood or bodily fluid [1]. Annually, approximately one million health workers experience this form of injury [2]. These injuries, no matter how small it may appear, pose a great risk to health workers as they expose them to various diseases such as Human Immunodeficiency Virus (HIV), Hepatitis B Virus (HBV) and Hepatitis C (HCV) infections [3,4]. As observed by Wilburn and Eikkemans [5], about 2 million cases of needle stick injuries lead to HIV, HBV, HCV infections. Wang et al., [6] have posited that approximately 9 to 42 per million healthcare workers die from these occupational injuries. Besides, even when the patient is not known to be a carrier of these diseases, the thought of being injured by a needle creates an atmosphere of emotional tension and distress for the healthcare worker.

Needlestick injuries usually occur among nurses and other health workers also involved include doctors, laboratory workers, and ancillary staff. The causes of these injuries are varied and include attempting to recap needles, manipulating needles, collision with other health workers among others. In developing countries, factors responsible for increasing needle stick injuries include excessive handling of contaminated needles and lack of sharp containers. The risk of contracting infectious diseases is particularly more pronounced in areas with a high prevalence of conditions like HIV and HBV [3]. It is estimated that 2.5 to $4.4 \%$ of HIV cases among health workers, $37 \%$ of HBV infections and $39 \%$ of HCV infections among health workers are as a result of needlestick injuries. After having a needle stick injury from a contaminated needle it is estimated that the chances of being infected are $1.2-10 \%$ for HCV [7,8], 10-30\% for HBV and 0.3$0.4 \%$ for HIV [8]. These figures are alarming as most developing countries are struggling with human resource and increasing incidence of these conditions may lead to manpower shortage [8]. These statistics suggest that being infected after a needle stick injury is an uncertain situation where the affected person lives in a bubble filled with the hope of not acquiring any infection and fear of what happens if an infection is acquired. For a young nurse with lots of productive years ahead, the thought of having to live with an infection that apparently has no cure could escalate various emotions such as helplessness and distress. Adequate support is therefore required beyond administering post-exposure prophylaxis.

In a survey by the Royal College of Nursing [9], most nurs- es started being afraid of the aftermath of needle stick injuries; with greater fear and stress in situations, nurses knew there is no employer policy covering prevention and reporting of the incident. The College, therefore, acknowledges the psychological harm associated with such incidents and have called for measures to protect health workers. Similar assertions have also been put forward by Moayed, Mahmoudi, Ebadi, and Nia [10] as they observed high levels of stress among nurses relating to needle stick exposure. Though these studies provide an overview of the phenomenon, what remains unclear are the emotional negotiations and unique experiences that the nurse goes through after the incident. Understanding these experiences could be vital in determining how to support the affected nurse after the incident. It is against this backdrop that this paper has been written to take readers on the author's personal journey after being involved in a needle stick injury.

\section{Method}

The study used the reflexive ethnography approach where the self is the focus of the study. Self- examination, and retrospection are used to gain insight into key events in relation to the author [11].

The self, being the focal point, helps to bring into perspective individual variation, cultural sensitivity and makes the account experiential, reflective and holistic [12]. Bloor also opines that the object of all clinical work is the patient's body [13] and the self as the focus of the study, gives a firsthand account from the author who is the best person to describe what they experienced in their own body [13]. An audit trail from the author's diary was used as a source of information and quotes made by others who happened to play a significant role in the event. This serves as a source of verification of quotes made by individuals involved in the event as stated in the study [11]. Allowing significant others to confirm that their quotes as stated were correct helps prevent the author from twisting the story and maintains the veracity of the story and not present a story that seeks only to serve the purposes of the author [11]. The identities of significant others were also protected.

\section{Results}

\section{How It Happened}

On the $12^{\text {th }}$ of November, 2017, in less than three months after being recruited as a nurse in a teaching hospital, I was attending to a patient with a $2^{\text {nd }}$ to $3^{\text {rd }}$-degree burns of the upper and lower limbs. This patient had no IV access as the numerous ones that 
had been set on different occasions had extravasated after some time. Due to this, she had not received the optimum amount of fluids that day. As the shift in charge, I knew I owed the patient a duty to care. Thus, I assessed her and realized she needed some fluids as the intake and output chart for the previous 24hours showed a negative balance. As per prescribed nursing interventions, I decided to secure peripheral venous access to commence IV hydration therapy. However, due to the extent of the injury which required extensive bandaging, there were limited options remaining with regards to the site for the IV cannulation process. I tried to find a vein in the antecubital fossa of the left arm. However, the skin around that area had become quite hard and as such in an attempt to get the needle into the vein, it slipped instead, pricking one of my fingers.

At that moment, I knew I had been pricked but I just could not believe it. I was hoping that no blood would ooze out so that I could convince myself that the injury was not deep enough.

However, blood started oozing out. I was numb for a moment and my mind was blank for a short while. Then my thoughts started racing. I started thinking about the few minutes preceding the procedure and I wished I had not attempted to pass the IV cannula. I was angry, not at anyone in particular but I was just angry as to why this could happen to me. I was only helping a patient in need and this is what I got in return. That felt really unfair. I started hoping that upon testing, the client would be HIV negative.

\section{Action taken}

I washed the area and discarded the items that had been used. Since it was a weekend and the Voluntary Counseling and Testing (VCT) Unit was closed I could not get help from there. I, therefore, went to triage, the serology lab and the TB ward, places I knew I could get a test kit or a test done but none of these places had any help for me in the form of testing. I started wondering why things should run this way on weekends. I came back to the ward and handed over to the afternoon staff as my shift was over. My colleague by way of encouraging me said

"Oh don't worry, as for this woman I don't think she has HIV, so relax, everything will be fine".

I changed my clothes and was about leaving the hospital when I had an idea to call a midwife for a test kit. She did not have the kit but she suggested that I go to the blood bank. It was at the blood bank that I explained the incident to the biomedical scientist and
I was asked to get a blood sample from the patient which I did. A test was run for HIV and Hep B. As I had taken a Hepatitis B vaccination, I was not worried because I knew I was protected against the condition. My worry was now about the possibility of acquiring HIV. I was worried because the patient having HIV meant that there was a probability that I would seroconvert and I also had to take PEP which I had heard of as having unpleasant side effects. It also meant that I would have to wait for six months before I could know the final outcome of the needle prick. Just as the results were about to be ready, a colleague from a different ward also came to the blood bank to retrieve blood product. When the biomedical scientist came out I was trying to get close to him so that if the results were not favorable my colleague would not hear anything to warrant any explanation but before I could get close enough he stated

\section{"The Hер B is non-reactive but the retro is reactive".}

I was dumb founded and angry not really at the outcome at this instance but for speaking so audibly to the hearing of my colleague. The thought that raged through my mind was not really the test results but:

"Was my colleague going to think that the sample is for me or for someone else? How will my colleague react to the news given the stigma associated with HIV in our setting?"

I was not in uniform so the situation to an uninformed person might seem that I had come to run my blood sample and per the results, I was retro reactive. I did not want anyone outside my unit to know about the incident because to me, the higher the number of people who knew the higher the stigma. I was disappointed at the biomedical scientist for the unprofessional conduct. By this time, the reality of the test outcome was beginning to dawn on me fully. I was not sure which emotion to respond to first: anger at the biomedical scientist or my worry about my colleague misinterpreting what she had heard and the fear that came with the test being positive.

To clear any ambiguity, I told my colleague about what had happened. She also encouraged me and after I told her that I had to go to the pharmacy, she said:

"Relax, everything will be fine".

Despite the reassuring sound, I did not feel the impact of those words because I was lost in the overwhelming mixed bag of emotions that had almost engulfed me at this point: anger, uncertain- 
ty, confusion and yet a little spark of hope still lingered within.

I went to the pharmacy and narrated the incident and the steps I had taken to the pharmacist. He gave me two doses (one for that time and one for the next morning before I visit the VCT Unit) of two drugs Lopinavir, Ritonavir combination and Zidovudine, Lamivudine combination. He wanted me to get water from close by but I told him I had water in my bag which I had left at the blood bank. He allowed me to take the drug to the blood bank where I took the drug at 3:35 pm.

\section{Carrying the Message Across}

Before going home I passed by the ward to let them know the results of the test and also post the results on the patient's folder. The expression on the faces of my colleagues was one of surprise and disbelief.

We have all been exposing ourselves all this while," one of my colleagues said.

The other staff that was not present were made aware to be cautious when handling the patient. Almost everyone who heard of it expressed a sense of surprise. I left the ward for the house and on my way home a lot of thoughts ran through my mind:

"What is going to happen to me if I test positive after the stipulated period?" "Am I never going to get married if I happen to turn positive?" "How am I going to handle this situation from this time till the time I take a final test after 6 months?" "Should I tell my family or not?". "If I decide not to tell my family, how do I keep it from them? Am I going to be strong enough or have the urge to further my education"?

When I got home I tried to act as if nothing had happened. I joined our usual lengthy family discussions so as not to show that I was disturbed to avoid any suspicion and bombardment with a series of questions as was characteristic of my family. I also didn't want my family to know because I knew for sure that they were going to be more worried than myself.

\section{Voluntary Counseling and Testing (VCT)}

The following morning I took the second dose and went to the VCT Unit where I was counseled and tested. I was negative for HIV and was referred to the Chest Clinic Pharmacy to see one particular pharmacist. I was hoping not to see any familiar face but just as I was entering the clinic I met a colleague who was passing by. I exchanged pleasantries and was happy she did not ask me any question. I got to the pharmacy and upon mentioning the name of the one I was asked to see, I was directed to a middle-aged man who welcomed me warmly and after I had told him of the situation took time to educate me about the drugs he was about to give me, the side effects and when to take some confirmatory tests. I was less apprehensive as I had been made aware of what to expect. I, however, knew it was not going to be easy.

\section{The Prophylaxis and Unending Questioning Journey}

I started taking the medication and eating well as I was told. I was expecting that whatever side effects would show up in some days so I was getting prepared for it but the onset was quite sooner than expected. On the first day post of taking the medication, I had diarrhea. From the second day whenever I swallowed the drugs, I experienced nausea, headache, fatigue, and severe weakness. I, however, had no choice than to continue taking the drugs as I knew they were going to help reduce or eliminate any risks of seroconversion. Diarrhea seized on the third day but the other symptoms persisted. The combination of the symptoms I was feeling affected me to the extent that when I woke up the only things I could do or think of doing were eating and sleeping. Other activities of daily living were things I did just to get by. At some point, I described how I was feeling as "pregnancy and malaria symptoms combined" even though I have not been pregnant before nor will I ever be but that was the best way I could describe it. The symptoms were so obvious that my family would recognize that there was something wrong with me. I, therefore, decided to spend at least five days a week on the ward and one at home so that I will give my "detective" family very little chance to detect something. I, therefore, made arrangements to put together some items I would need for my upkeep on the ward even though I had been told to seek an excuse of duty. I could not send the actual drug containers home and had to put them in unlabeled envelopes for fear of my younger sisters finding an "uncommon" drug in my bag asking me about it or "googling it". On the days that I spent at home, my family kept asking me what is wrong with me and if I have sought treatment. I told them that:

\section{"I think it is malaria so I have taken an antimalarial"}

When on the third week I was still weak, they now asked what kind of malaria it was that was not subsiding even after taking medications. I then had to find a smarter lie before my malarialie could be exposed. I then told them that the staff in my ward had been given some drugs as prophylaxis and the drugs were quite strong so most of the people who took them were also feeling 
weak like myself. From their expressions, I knew they did not fully buy it but they probably didn't want to disturb a sick person and because I was at the hospital most of the time they thought I was safe. The days that followed were days of sleeping, waking up with headaches, feeling dizzy and weak. Through these days the staff in my ward were very supportive through the encouraging words and checking up on me. On days that I was feeling less weak, I tried to teach student nurses on my ward so that I don't lie down all the time even though I was teaching them before the incident. I also tried to read some publications on needle pricks and the chances of seroconversion after going through prophylaxis. It was not all the findings that were soothing but there were some that gave me hope; the ones that stated that starting the prophylaxis within 24 hours greatly reduced the chances of seroconversion. There were days that I thought my body was getting used to the drug (for example on the $9^{\text {th }}$ day) but the symptoms came back as they had been. I was always dreading the time that I had to take the drug. I kept on struggling through the symptoms with the hope that at the end of one month I will be done and I would have a reduced risk of seroconversion. All through this period, there were days that I managed to read some research papers to get a fair idea of my chances of seroconversion or not. However, with any percentage I saw, I realized that I could be on the positive side or the negative side of the statistics and this scared me so I just stopped reading and hoped that no matter what the statistics prove the outcome of my test after six months would be favorable. A colleague of mine at work told me that she knew of another colleague who had being a victim of needlestick injury more than once and had tested negative in all instances. I got some encouragement from this statement as I had already been told by the biomedical scientist who tested me that he had also been pricked three times and in all cases even though the patients were positive, he turned out to be negative. These statements gave me hope on a regular basis but on some days a lot of questions run through my mind; what is going to be the outcome? If the outcome is unfavorable, how is my family going to take it, how are my work colleagues going to interact with me and are they going to keep it confidential? what were people going to assume as the cause of the condition? All these questions made me disturbed for some time but at some point, I made it a point to be more hopeful than afraid and that was helpful throughout the months. That notwithstanding, for weeks, whenever I woke up, the first thought that came to mind was:

"How are things going to turn out?"

\section{Post-Prophylaxis}

Finally the day I was to take the last dose came. It was as if I was being initiated into a new world: a world where I could look forward to the next day and be hopeful. Even though I was weak and would not know my final status until some months later, I was very happy that the "pregnancy and malaria" feeling was over. I could now have a normal life where I would not put all other things on hold except eating, sleeping and basic activities of daily living. It took some days before I could feel like my 'old self'. The struggle had now become psychological. There were days that I did not think of it at all and there were days that I could think of nothing else especially on days that a confirmatory test was close by ( 3 months and 6 months post-incident).

On the $3^{\text {rd }}$ month, I tested negative and was not so relieved because I knew it was not conclusive. I was truly relieved when I tested negative on the $6^{\text {th }}$ month and even took another test on the $8^{\text {th }}$ month just to be fully sure. The days of fear, anxiety, and uncertainty were now over. Now I know I am negative and I treat every patient as positive until proven otherwise and anytime the incident comes to mind, I am happy that things turned out positively. I, however, take extra caution when handling needles and also tell students and interns about my story so that they also take caution because the experience I had is not one I would want to have ever again and I would not want anyone else to have a similar experience.

\section{Discussion}

The several attempts of securing an intravenous access could be avoided and help prevent NSI by paying attention to the passing of a central venous catheter in burns patients in cases where the routine intravenous cannula may not be suitable due to the areas involved in burns, as evidence suggests that the elimination of unnecessary injections is a primary prevention of NSIs [5]. The use of needleless intravenous systems if adopted could help prevent some avoidable NSIs [5] Having some knowledge about what to do after an NSI was helpful as it directed my actions after the injury. However recent evidence suggests that knowledge of PEP among health workers in most settings are low and this can be dangerous as poor knowledge may affect a person's decision and timing of taking PEP which may eventually lead to positive seroconversion [2].

Education of health workers and students on prevention of NSI and PEP as well as workshops on a regular basis could be beneficial and should be given attention as it has been shown that discussions on PEP are not given attention even in areas where there is a lot of campaign on HIV [2].

The ethical principle of confidentiality is based on the premise 
that individuals have the right to keep their affairs private and their consent is required to share such private information to others [14].The passing on of information regarding the test to the hearing of another health worker without consent could, therefore, be considered a breach of confidentiality. Health workers should make it a point to adhere strictly to the ethics of confidentiality even when the patient in question is a health worker as fear of confidentiality being breached can demotivate patients from seeking care especially in the case of HIV [15] and may lead to underreporting.

The statement "Oh don't worry, as for this woman I don't think she has HIV, so relax, everything will be fine" although was an attempt to reassure me, gives some indication of how the judgment of the HIV status of some patients are not objectively made which can lead to unintentional or unconcerned exposure. If confidentiality is strictly upheld, it would be beneficial to test all patients for HIV but that may raise ethical issues of autonomy and would have cost implications. As such it would be helpful to be cautious with each patient as if they were infected until proven otherwise. Health workers in the burns unit especially nurses (as they spend long hours with patients) should be more cautious in handling burns patients as exudate from burns, and not only blood is considered high risk for the transmission of HIV [16].

The time taken in getting the source patient tested was not prompt as several units had to be visited due to the unavailability of rapid test kits. It would be helpful if these rapid test kits and other forms of tests are made readily available in most high-risk units as this has been proven to prevent the unnecessary commencement of PEP avoiding the side effects and possible toxicity [16]

From this experience, it could also be said that since I had already been vaccinated against Hep B I was not perturbed by it. This, however, is not the case for some health workers. As health workers are exposed on a regular basis to $\mathrm{HBV}$, vaccination of health workers and students against Hep B should be made a priority since the chronic form has a $25 \%$ chance of death from cirrhosis or liver cancer [17].

The occupational exposure of health workers to HIV can be very stressful to the extent that some health workers have been reported to suffer from Post-Traumatic Stress Disorder (PTSD) after the exposure. [18]. The stigmatization and social isolation that come with a diagnosis of HIV contribute to the immense psychological stress experienced by health workers who have needle stick injuries [19]. This makes it necessary for exposed health workers to receive some form of psychological care through institutional support systems in the organizations in which they work. From my experience, psychological support if taken in this approach would be helpful: The PEP team choosing representatives in each unit or department to be on the lookout for NSI cases and reaching out to them rather than waiting for the victims to reach out to them as these victims may not have the strength to do so, supporting these victims though VCT and weekly reviews by a psychologist and assigning a co-worker to casually check on them from time to time. As was seen from this experience, apart from the pharmacological care and brief counseling prior to testing, the words of encouragement from colleagues, and the information I received from other colleagues on how others had tested negative after several exposures were all ways of supporting and encouraging me through those uncertain and fear-ridden times and they were very helpful.

However, these were not formal or institutionalized and these benefits could have been lost had the people involved decided to withhold it. Despite the institution having a PEP team that can be contacted in case of NSI, the contact approach is from victim to team and for that matter victim who do not know of the existence of this team, how to contact them or lacking the will to contact them may not benefit from their resources. From my experience, it could, therefore, be of great help if an institutional form of support, psychological or in any other form is provided for victims of needle stick injuries in institutions in which there is no such system and reviews made in institutions where such support is in a "victim to PEP team approach". This will help deal with the stress, uncertainty, and fear as evidence suggests that if these are not handled well can affect the wellbeing of health workers and lead to occupational and behavioral changes that affect the quality of care given to people living with HIV [4]. 


\section{References}

1. Jahan S (2005) Epidemiology of needlestick injuries among health care workers in a secondary care hospital in Saudi Arabia. Ann Saudi Med 25: 233-8.

2. Owolabi RS, Alabi P, Ajayi S, Daniel O, Ogundiran A, Akande TM, et al. (2012) Knowledge and Practice of Post-Exposure Prophylaxis ( PEP ) against HIV Infection among Health Care Providers in a Tertiary Hospital in Nigeria. J IntAssoc Physicians AIDS Care 11: 179- 183.

3. Gurubacharya DL, Mathura KC, and Karki DB (2003) Knowledge, attitude and practices among health care workers on needle-stick injuries. Kathmandu Univ Med J1: 91-94.

4. Mbaisi EM, Ng'ang' a Z, WanzalaP (2013) Prevalence and factors associated with percutaneous injuries and splash exposures among health-care workers in a provincial hospital, Kenya, 2010. Pan Afr Med J 8688: 1-8.

5. Wilburn SQ, Eijkemans G (2013) Preventing Needlestick Injuries among Healthcare Workers: A WHO-ICN Collaboration. Int J Occup Environ Health 3525.

6. Wang H, Fennie K, Burgess J, Williams AB (2003) A training program for prevention of occupational exposure to bloodborne pathogens : impact on knowledge, behavior, and incidence of needle stick injuries among student nurses in Changsha, People 's Republic of China. J AdvNurs. 41:187-194.

7. Sadoh WE, Fawole A, Sadoh AE, Oladimeji A (2006) Practice of Universal Precautionsamong Healthcare Workers. J Natl Med Assoc 98:722-726.

8. Wicker S, Ludwig A, Gottschalk R, Rabenau HF (2008) Needlestick injuries among health care workers : Occupational hazard or avoidable hazard ? Middle Eur J Med 486-487.

9. Ball, J. Pike G (2008) Needlestick injury in 2008 Results from a survey of RCN members. R Coll Nursing, 20 Cavendish Square, London.

10. Moayed MS, Mahmoudi H, Ebadi A, Nia HS (2016) Stress and Fear of Exposure to Sharpsin Nurses. Iran J Psychiatry Behav Sci 10.

11. deVos A S, Strydom H, Fouché CB, \& Delport CSL (2011) Research at grassroots: For the social sciences and human service professions (4th ed.). Pretoria, South Africa: VanSchaik. 12. Lohmann RI, Kahn M, Rosi P, Fajans J (2009) Review of Reflexive Ethnography: A Guide to Researching Selves and Others. Anthropol Rev 19: 109-11.

13. Bloor M (2001) Handbook of Ethnography. Paul Atkinson, Amanda Coffey SD, and LL, editor. London: SAGE Publications.

14. Wiles R, Crow G, Heath S, Wiles R, Crow G, Heath S, et al. (2006) Anonymity and confidentiality. In: ESRC Research Methods Festival, University of Oxford. ESRC National Centre for Research Methods.

15. Vaga BB, Moland KM, Blystad A (2016) Boundaries of confidentiality in nursing care for mother and child in HIV programs. Nurs Ethics 23: 576-586.

16. Hamlyn E, Easterbrook P (2007) Occupational exposure to HIV and the use of post-exposure prophylaxis. Occupational Med 57: 329-336.

17. Okeke E N, Ladep N G, Agaba E I MAO. (2008) Hepatitis B Vaccination Status and Needlestick Injuries among Medical Students in a Nigerian University. Niger J Med 17: 330-332.

18. Worthington MG, Ross JJ, Bergeron EK (2006) Posttraumatic Stress Disorder After Occupational HIV Exposure: Two Cases and a Literature Review. Infection Control \& HospitalEpidemiology. Cambridge University Press 27: 215-217.

19. Zukoski AP, Thorburn S (2008) Experiences of Stigma and Discrimination among adults living with HIV in a Low HIV - Prevalence Context : A Qualitative Analysis. AIDS Patient Care STDS 23.

Submit your manuscript to a JScholar journal and benefit from:

ฯ Convenient online submission

ब Rigorous peer review

I Immediate publication on acceptance

ब Open access: articles freely available online

I High visibility within the field

ब Better discount for your subsequent articles

Submit your manuscript at http://www.jscholaronline.org/submit-manuscript.php 